\title{
Editorial
}

\section{Metastatic Colorectal Cancer}

\author{
Alessandro Passardi ${ }^{1}\left(\mathbb{D}\right.$, Giorgia Marisi $^{2, *} \mathbb{C}$ and Paola Ulivi ${ }^{2}$ \\ 1 Medical Oncology Unit, IRCCS Istituto Romagnolo per lo Studio dei Tumori (IRST) “Dino Amadori”, \\ 47014 Meldola, Italy; alessandro.passardi@irst.emr.it \\ 2 Biosciences Laboratory, IRCCS Istituto Romagnolo per lo Studio dei Tumori (IRST) “Dino Amadori”, \\ 47014 Meldola, Italy; paola.ulivi@irst.emr.it \\ * Correspondence: giorgia.marisi@irst.emr.it
}

Citation: Passardi, A.; Marisi, G.; Ulivi, P. Metastatic Colorectal Cancer. Cancers 2021, 13, 6346. https:// doi.org/10.3390/cancers13246346

Received: 14 December 2021 Accepted: 15 December 2021 Published: 17 December 2021

Publisher's Note: MDPI stays neutral with regard to jurisdictional claims in published maps and institutional affiliations.

Copyright: (c) 2021 by the authors. Licensee MDPI, Basel, Switzerland. This article is an open access article distributed under the terms and conditions of the Creative Commons Attribution (CC BY) license (https:/ / creativecommons.org/licenses/by/ $4.0 /)$.
International experts in the study of metastatic colorectal cancer (mCRC) present this series of 14 articles (eleven original articles and three literature reviews).

The treatment options for patients with $\mathrm{mCRC}$ have changed considerably in recent years, thanks to the introduction into clinical practice of monoclonal antibodies directed against molecular targets. To date, the following two types of monoclonal antibodies have been approved for clinical use in mCRC: the antiangiogenic agents, Bevacizumab, Ramucirumab and Aflibercept, and the anti-epidermal growth factor receptor (EGFR) antibodies, Cetuximab and Panitumumab. A multicenter Italian observational study (FABIO project) was designed to evaluate the impact of adding the target drugs, Bevacizumab and Cetuximab, to first line chemotherapy in terms of survival and costs. Trial results indicated that first-line biological therapy did not improve long-term overall survival and was associated with higher costs as compared to standard chemotherapy [1]. Gelsomino et al. performed a pooled analysis to evaluate the impact of anti-angiogenics in patients with pretreated BRAF-mutant $\mathrm{mCRC}$. The analysis showed a significant advantage from combining chemotherapy to these agents over the placebo in terms of OS (HR 0.50, 95\%CI 0.29-0.85) $(p=0.01)$ [2]. Unfortunately, there are currently no validated markers of sensitivity or resistance to chemotherapy and antiangiogenic drugs. The study by Suenaga et al. showed that single nucleotide polymorphisms (SNPs) in genes involved in nucleotide excision repair (NER) of platinum-induced DNA damage are associated with the superior efficacy of FOLFOXIRI and Bevacizumab, compared with FOLFIRI plus Bevacizumab for mCRC patients in the TRIBE trial [3].

Next to antiangiogenic and anti-EGFR agents, the introduction of checkpoint inhibitors provided important achievements in a small group of mCRC patients with microsatellite unstable (MSI-high) tumors. Current results in patients with microsatellite stable (MSS or MSI-low) tumors are disappointing, even if there are several ongoing clinical trials aiming at extending the efficacy of immunotherapy beyond the MSI-high subgroup [4]. In this context, another important aspect is the role of the biological heterogeneity and low inherent immunogenicity of colorectal cancer. The review of Kalanxhi et al. summarized the immunological characteristics of colorectal cancer, the effects that standard-of-care treatments have on the immune system, and the opportunities arising from combining immune checkpoint-blocking therapy with immune-modulating conventional treatments [5].

A topic of interest in the management of $\mathrm{mCRC}$ is the evaluation of the response to anticancer treatment. Vera et al. reported the interesting results of the AVAMET study, indicating that computed tomography-based morphological criteria (CTMC) might represent a better marker of pathological response than RECIST in patients with potentially resectable CRC liver metastases [6]. Patients with $\mathrm{mCRC}$ rarely develop brain metastases. In these patients, the prediction of survival ( $<$ or $>6$ months) is important for the decision-making process. Rades et al. developed an easy-to-use survival score based on two independent predictors (performance status and absence/presence of non-cerebral metastases), which permitted them to predict survival with higher accuracy than existing tools [7]. 
Genome-wide DNA methylation of colorectal cancer metastasis revealed a higher methylation status of metastasis with respect to primary tissue, and showed that the methylation pattern of FIGN, HTRA3, BDNF, HCN4, and STAC2 is associated with a poor prognosis [8]. Moreover, high preoperative $K R A S$ mutation fractional abundance was demonstrated to be a poor prognostic factor in patients undergoing liver metastasectomy. The combination of preoperative KRAS mutation levels with CEA levels seems to give the best prognostic value in this setting of patients [9]. Another study applied a wide integrative omics approach on liver metastasis, and revealed that in synchronous metastasis BRCA1 protein was co-localized in Ito, Kupffer, and endothelial cells in the majority of cases, whereas this occur rarely in metachronous metastases, pointing out a role of BRCA1 as a potential TME biomarker [10].

Furthermore, some studies investigated new potential therapeutic targets in CRC. Iyer et al. suggested that piR-24000 might serve as a potential novel biomarker or a therapeutic target in CRC, specifically in patients presenting with an advanced, aggressive clinical phenotype [11]. Schulte am Esch et al. presented the novel colorectal cancer cell lines BKZ-2 and BKZ-3 as promising cellular in vitro models for colorectal carcinomas and identified the MYC/NMYC molecular pathway involved in cancer stem cells (CSC)induced carcinogenesis with relevant therapeutic potential [12]. Cancer stem cells (CSC), which are a small subpopulation of tumor cells with high plasticity driving tumor growth and metastasis, are crucial mediators of cancer relapse.

Moreover, another interesting topic is the study of adenoma-carcinoma sequence. Boman et al. investigated the kinetics of adenoma and CRC development in familial adenomatous polyposis (FAP) and sporadic cases in order to identify mechanisms that may explain how changes in tissue dynamics and processes contribute to CRC development. The authors suggests that mutation in the adenomatous polyposis coli (APC) gene increases autocatalytic tissue polymerization and induces tumor tissues to autocatalyze their own progressive growth, which drives tumor development in the colon [13].

Finally, there is now the opportunity to integrate genomic and transcriptomic analyses with advanced experimental models. The integration of omics and advanced mouse models of mCRC with more clinical-like criteria of the evaluation of antitumor efficacy in preclinical studies, could accelerate the anticancer discovery process and provide new weapons against cancer [14].

Conflicts of Interest: The authors declare no conflict of interest.

\section{References}

1. Franchi, M.; Garau, D.; Kirchmayer, U.; Di Martino, M.; Romero, M.; De Carlo, I.; Scondotto, S.; Corrao, G. Effectiveness and Costs Associated to Adding Cetuximab or Bevacizumab to Chemotherapy as Initial Treatment in Metastatic Colorectal Cancer: Results from the Observational FABIO Project. Cancers 2020, 12, 839. [CrossRef] [PubMed]

2. Gelsomino, F.; Casadei-Gardini, A.; Rossini, D.; Boccaccino, A.; Masi, G.; Cremolini, C.; Spallanzani, A.; Viola, M.G.; Garajovà, I.; Salati, M.; et al. The Role of Anti-Angiogenics in Pre-Treated Metastatic BRAF-Mutant Colorectal Cancer: A Pooled Analysis. Cancers 2020, 12, 1022. [CrossRef] [PubMed]

3. Suenaga, M.; Schirripa, M.; Cao, S.; Zhang, W.; Yang, D.; Cremolini, C.; Murgioni, S.; Lonardi, S.; Ning, Y.; Okazaki, S.; et al. Single Nucleotide Polymorphisms in MiRNA Binding Sites of Nucleotide Excision Repair-Related Genes Predict Clinical Benefit of Oxaliplatin in FOLFOXIRI Plus Bevacizumab: Analysis of the TRIBE Trial. Cancers 2020, 12, 1742. [CrossRef] [PubMed]

4. Marmorino, F.; Boccaccino, A.; Germani, M.M.; Falcone, A.; Cremolini, C. Immune Checkpoint Inhibitors in pMMR Metastatic Colorectal Cancer: A Tough Challenge. Cancers 2020, 12, 2317. [CrossRef] [PubMed]

5. Kalanxhi, E.; Meltzer, S.; Ree, A.H. Immune-Modulating Effects of Conventional Therapies in Colorectal Cancer. Cancers 2020, 12, 2193. [CrossRef] [PubMed]

6. Vera, R.; Gómez, M.L.; Ayuso, J.R.; Figueras, J.; García-Alfonso, P.; Martínez, V.; Lacasta, A.; Ruiz-Casado, A.; Safont, M.J.; Aparicio, J.; et al. Correlation of RECIST, Computed Tomography Morphological Response, and Pathological Regression in Hepatic Metastasis Secondary to Colorectal Cancer: The AVAMET Study. Cancers 2020, 12, 2259. [CrossRef] [PubMed]

7. Rades, D.; Nguyen, T.; Janssen, S.; Schild, S.E. An Easy-To-Use Survival Score Compared to Existing Tools for Older Patients with Cerebral Metastases from Colorectal Cancer. Cancers 2020, 12, 833. [CrossRef]

8. Ili, C.; Buchegger, K.; Demond, H.; Castillo-Fernandez, J.; Kelsey, G.; Zanella, L.; Abanto, M.; Riquelme, I.; López, J.; Viscarra, T.; et al. Landscape of Genome-Wide DNA Methylation of Colorectal Cancer Metastasis. Cancers 2020, 12, 2710. [CrossRef] 
9. Polivka, J.; Windrichova, J.; Pesta, M.; Houfkova, K.; Rezackova, H.; Macanova, T.; Vycital, O.; Kucera, R.; Slouka, D.; Topolcan, O. The Level of Preoperative Plasma KRAS Mutations and CEA Predict Survival of Patients Undergoing Surgery for Colorectal Cancer Liver Metastases. Cancers 2020, 12, 2434. [CrossRef] [PubMed]

10. Gerovska, D.; Larrinaga, G.; Solano-Iturri, J.D.; Márquez, J.; García Gallastegi, P.; Khatib, A.-M.; Poschmann, G.; Stühler, K.; Armesto, M.; Lawrie, C.H.; et al. An Integrative Omics Approach Reveals Involvement of BRCA1 in Hepatic Metastatic Progression of Colorectal Cancer. Cancers 2020, 12, 2380. [CrossRef] [PubMed]

11. Iyer, D.N.; Wan, T.M.-H.; Man, J.H.-W.; Sin, R.W.-Y.; Li, X.; Lo, O.S.-H.; Foo, D.C.-C.; Pang, R.W.-C.; Law, W.-L.; Ng, L. Small RNA Profiling of piRNAs in Colorectal Cancer Identifies Consistent Overexpression of piR-24000 That Correlates Clinically with an Aggressive Disease Phenotype. Cancers 2020, 12, 188. [CrossRef]

12. Schulte am Esch, J.; Windmöller, B.A.; Hanewinkel, J.; Storm, J.; Förster, C.; Wilkens, L.; Krüger, M.; Kaltschmidt, B.; Kaltschmidt, C. Isolation and Characterization of Two Novel Colorectal Cancer Cell Lines, Containing a Subpopulation with Potential Stem-Like Properties: Treatment Options by MYC/NMYC Inhibition. Cancers 2020, 12, 2582. [CrossRef]

13. Boman, B.M.; Guetter, A.; Boman, R.M.; Runquist, O.A. Autocatalytic Tissue Polymerization Reaction Mechanism in Colorectal Cancer Development and Growth. Cancers 2020, 12, 460. [CrossRef] [PubMed]

14. Porru, M.; Zizza, P.; Panera, N.; Alisi, A.; Biroccio, A.; Leonetti, C. Harnessing Omics Approaches on Advanced Preclinical Models to Discovery Novel Therapeutic Targets for the Treatment of Metastatic Colorectal Cancer. Cancers 2020, 12, 1830. [CrossRef] [PubMed] 